SHS Web of Conferences 10, 00032 (2014)

DOI: $10.1051 /$ shsconf $/ 20141000032$

C Owned by the authors, published by EDP Sciences, 2014

\title{
Self-assessment analysis of health and physical activity level of military personnel
}

\author{
L. Plavina ${ }^{1}$ and H. Karklina ${ }^{2}$ \\ ${ }^{1}$ National Defence Academy of Latvia, Latvia \\ ${ }^{2}$ Rīga Stradiòš University, Latvia
}

\begin{abstract}
Sport and physical activity is important and compulsory for military staff. They determine the execution of service duties and tasks. Respondents with low level of physical activity have difficulties achieving required fitness level and pass the annual physical tests.

Staff officers aged 28 to 40 years completed questionnaires in 2009 ( $n=22), 2010$ $(n=30)$ and $2012(n=39)$. Each questionnaire included twenty one questions which were then evaluated in points. The answers allowed us to collect information regarding their physical activity during service hours as well as after the working day. Questionnaires included also issues on harmful habits - sleep duration, smoking and use of alcohol; selfesteem of body mass as well.

The respondents were divided into four groups according to the level of physical activity: low, moderate, good, high.

The percentage of respondents with a high and good level of physical activity has increased from $22.7 \%$ to $68.9 \%$ during the analysed time period.

Morning exercises and hardening (fitness) procedures were not popular for military personnel. However, physical activities during the working hours have slightly increased: $31.8 \%, 43.3 \%$ and $48.9 .3 \%$ respectively.

In study years, it was found that respondents try to follow healthy eating habits and sleep regime. There is a slight decrease of respondents with obese and there is a slight increase of $22.7 \%$ to $27.6 \%$ of the respondents who are regular smokers .
\end{abstract}

\section{Introduction}

Physical activity, which is closely associated with physical fitness, is an indispensable part of daily routine of the military personnel $(1,2,3)$. Physical fitness characterizes an individual's cardio respiratory status, muscular strength and endurance, as well as velocity and coordination, it comprises characteristic morphological and functional properties, which provide ability for individual to do a physical activity $(4,5)$. The fitness level of military personnel determines the quality of performance of official duties $(6,7,8)$, therefore the military personnel take regulatory yearly exercises in three different kinds of sports, which characterize the degree of muscular strength and endurance: $3000 \mathrm{~m}$ run for men and $1500 \mathrm{~m}$ run for women, exercises for upper body lift, and arm bending and straightening-ups. The ability to perform these normative depends on each individual's physical fitness level.

Several international studies show evidence of decreased fitness levels among military personnel (9).

This is an Open Access article distributed under the terms of the Creative Commons Attribution License 4.0, which permits unrestricted use, distribution, and reproduction in any medium, provided the original work is properly cited. 
SHS Web of Conferences

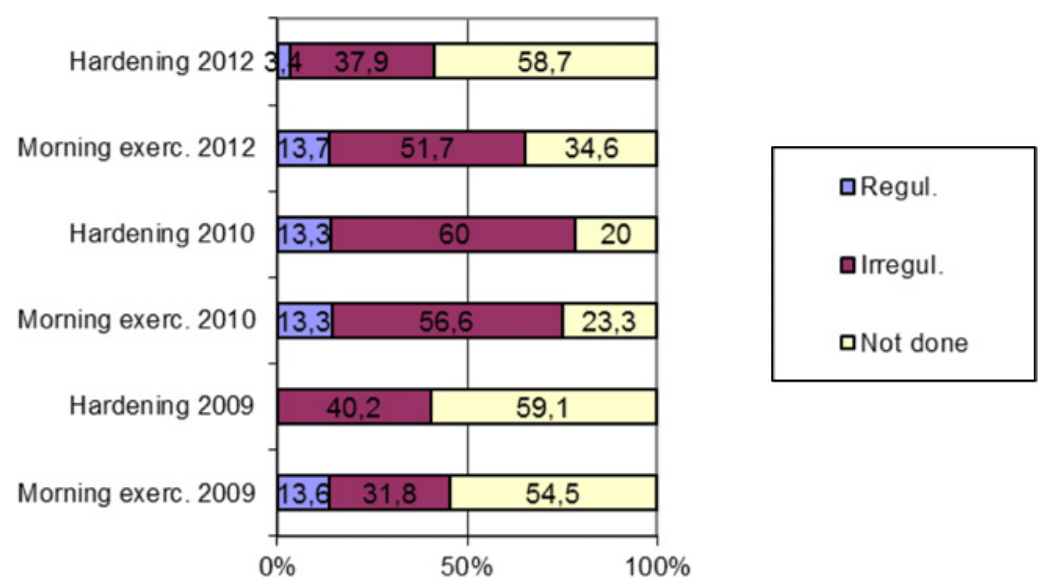

Figure 1. Evaluation of respondents' doing morning exercises and fitness procedures (\%).

\section{Material and methods}

The cross-sectional study, carried out in 2009 and 2012, when 91 male respondents, working in the National Armed Forces Joint Headquarters of the Ministry of Defence of the Republic of Latvia, and whose length of service in the National Armed Forces had lasted from 7 till 14 years, were recorded and screened anthropometrically.

In 2009, the respondents' age was from 28 to 37 years, but in 2010 - from 28 to 36 years and in 2012 - from 29 to 40 years.

The study participants filled in a structured questionnaire which included questions on individual and organized physical load both on working days, and on days off, questions on eating habits and length of sleep, the days missed from service due to the illness, specifying the reason of absence, as well as an individual's self-assessment of health. The respondents were asked to fill in the questionnaire on the first half of the day.

Respondents also filled in an anonymous questionnaire on smoking and alcohol use.

Each answer was allocated a certain number of scores. As a result of the data statistical analysis and processing, the total level of the respondents' physical activities determined in each year's group was analysed.

This article describes only the results of the screening questionnaire.

\section{Results}

Questionnaire data on the respondents' attitude to morning exercises and fitness procedures are depicted in the graphical Figure 1. Morning exercises include aerobic exercises, in which moderate intensity aerobic load with dynamic strength and stretching exercises are combined. When answering the question on doing the morning exercises, about $2 / 3$ of respondents in examined groups gave a positive answer. Morning exercises during study period regularly were done by similar percentage of respondents $(13.6 \%$ in $2009,13.3 \%$ in 2010 and $11,1 \%$ in 2012). The number of respondents who were not doing morning exercises was $54.5 \%$ in $2009,23.3 \%$ in 2010 and $34.4 \%$ in 2012 .

In order to assess one's attitude to fitness procedures, there were questions asked: whether an individual performs water procedures at home - brushing oneself with a damp towel, cold water procedure or contrast shower, as well as exercises outdoors at least twice a week. 
Int. Conf. SOCIETY. HEALTH. WELFARE.

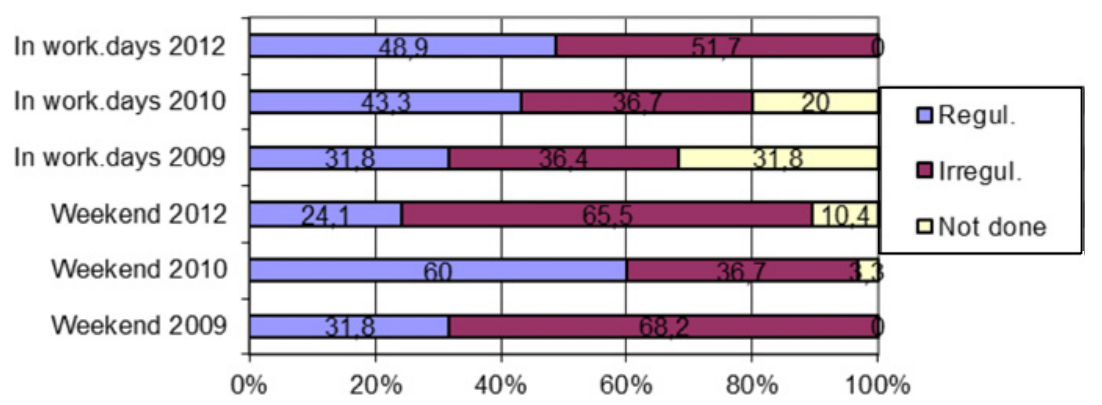

Figure 2. Respondents' sports activity rate and length on working days and on days off (\%).

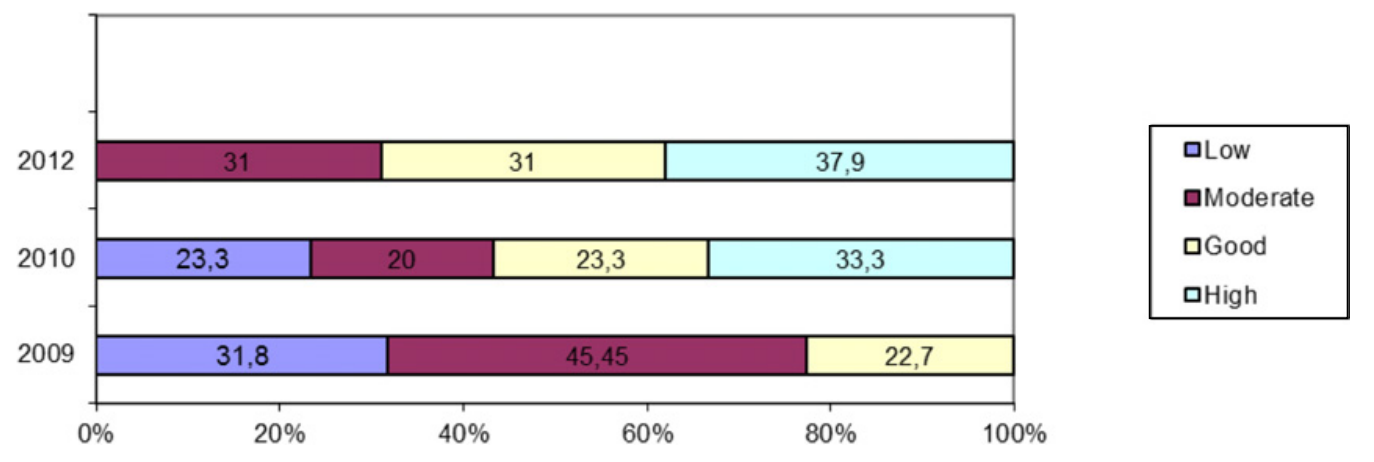

Figure 3. Division of respondents into groups by physical activity level (\%).

Partially positive responses in 2009 were received in $40.2 \%$ of cases, these respondents were doing hardening or fitness procedures irregularly. The situation improved considerably in $2010-13.3 \%$ respondents were undertaking fitness procedures regularly and there was an increase $19.8 \%$ of those people who, though irregularly, did these exercises. In 2012, only 3.4\% of respondents were doing these procedures regularly but $37,9 \%$ of them - irregularly.

A graphical Figure 2 is drawn depicting combined answers to questions of military personnel's individual and organized moderate and high intensity sports activities, duration of which are at least two hours, both outside in daily working hours, at weekends and on days off. In 2012, the number of those respondents who were doing regular physical load exercises on days off $(31.8 \%$ in $2009,60 \%$ in 2010 , and in $73 \%$ in 2012) increased almost twice.

The greatest part of the respondents $-31.8 \%$ choose sports activities during the week days (in 2009), 43.3\% (in 2010), and 48.9\% in 2012. During the working days 6\% (in 2009), $18.2 \%$ (in 2010) and $44.4 \%$ (in 2012) of respondents devote not more than two hours for sports activities, but $4.5 \%$ (in 2009), $10 \%$ (in 2010) and 6.8\% (in 2012) of respondents do sports activities for about 6-8 hours in total.

Questionnaire responses rendered the information on the question whether the respondents on their way to work and back go on foot (of moderate intensity load, not less than by 20 minutes), by bicycle (of low or moderate intensity load, if the distance is at least $10 \mathrm{~km}$ ), or use the public transport.

The results acquired prove that walking to the service was not acceptable for $99.8 \%$ of respondents in 2009,36.7\% of respondents in 2010, and 34.5\% of respondents in 2012.

Extra information and the attitude to physical load was obtained by answering to the question on the use of the elevator at work and at home. Results showed that 68.2\% (2009), 68.3\% (2010) and 79.3\% preferred climbing the stairs. 
SHS Web of Conferences

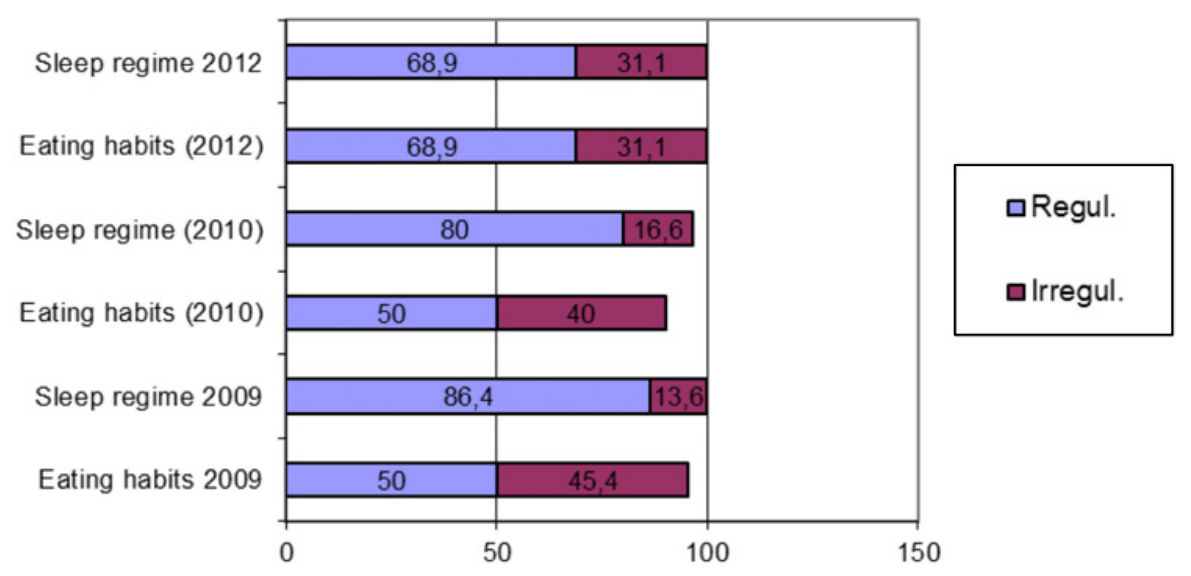

Figure 4. Healthy eating habits and sleep regime (\%).

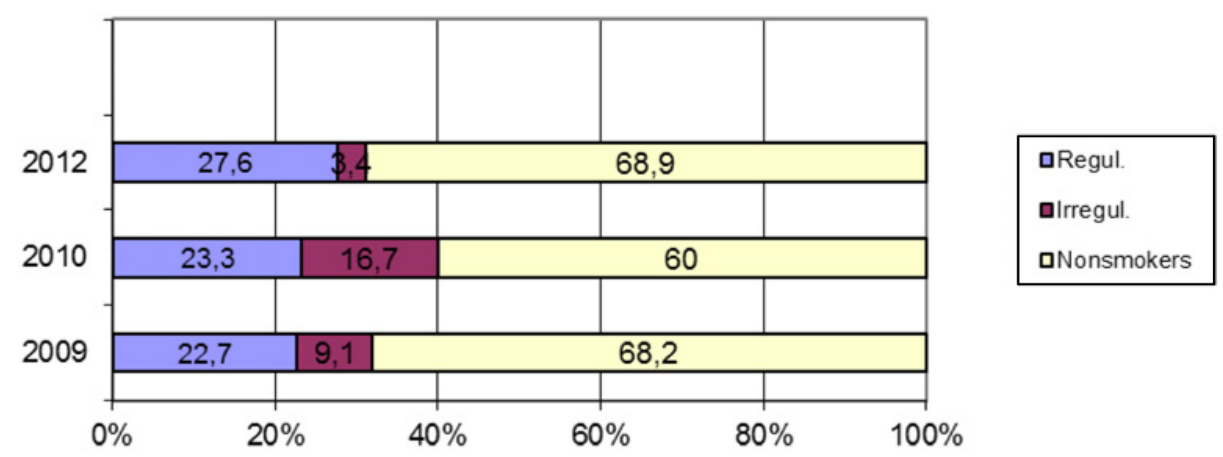

Figure 5. Respondents' opinion on smoking (\%).

After statistical processing of the acquired data of the questionnaire and assessing the total physical activity level by score, the respondents were divided into four groups: according to low, moderate, good and high physical activity level. Results show that the situation has improved - the group whose physical activity level was recognized as high increased to 37.9\% of cases in 2012 (Fig. 3).

Percentage rating of respondents' self-assessment on sleep and eating regime is depicted in graphical Figure 4. The majority of military personnel (about $80 \%$ ) have a sufficient length of night sleep (6-7 hours) and the sleep regime is regular.

In examined groups, under study in 2009 and 2010, the positive response on healthy eating habits and use of qualitative food was given only by $50 \%$ of respondents. In 2012, the situation has improved slightly - the number of respondents' increases to $68.9 \%$

Anonymous responses on smoking, specifying how many cigarettes are smoked per day, are summarized in Fig. 5. In examined groups, the situation was similar, non-smokers were more than half, however, in 2010, the tendency for irregular smokers was evident to increase in percentage. In 2010, regular smokers were $23.3 \%$ of respondents, but in 2012, they were $27.6 \%$.

Study participants' self-assessment on the body mass show that, in $2009-63.6 \%$, and in 2010 $-60.0 \%$, but in $201255.1 \%$, of respondents are of the opinion to be overweight or obese.

$77.3 \%$ of respondents have missed work of five working days due to the illness in 2009, a little more (80\%) respondents in 2010, and 62.1\% in 2012. 
Int. Conf. SOCIETY. HEALTH. WELFARE.

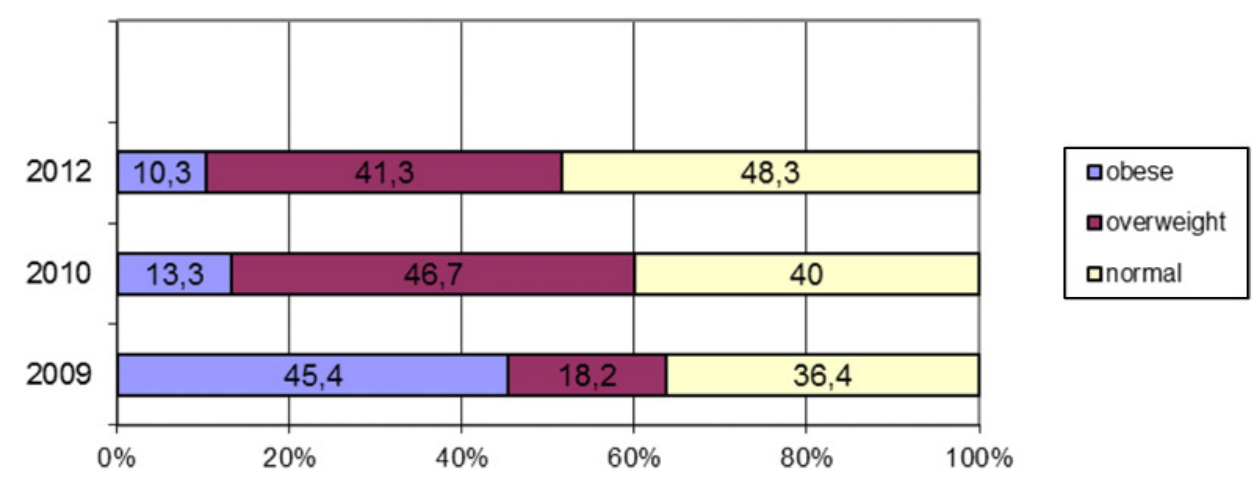

Figure 6. Respondents' opinion on body mass (\%).

$4.5 \%$ of respondents have missed work for longer than 15 days due to the illness in $2009,6.6 \%$ in 2010 , and $6.8 \%$ in 2012 . The main reasons of missing work for respondents were traumas, respiratory diseases and musculoskeletal system diseases.

\section{Discussion}

Everybody needs physical activity, but especially those representatives of profession whose direct job responsibilities and the quality of their performance depends on physical working abilities. Physical activity is characterized by the intensity of exercises or daily physical work intensity (low, moderate, good, high), duration and frequency. Therefore, the questionnaire developed during the study on the daily performed physical activities allows assessing the physical activity level of officers involved into the National Armed Forces Joint Headquarters of the Republic of Latvia. Although all study participants have been able to pass all normative characterizing strength and endurance, their physical activity level and the attitude towards physical activities are different. The duty of each military official is to withstand and promote the physical fitness and endurance during service. The greater is the physical activity, the better is individual's physical fitness and health; this is also reflected in similar studies in other countries (10).

Morning exercises have a beneficial effect on the body in developing job skills, therefore worries are caused by the fact that morning exercises were not done by $23.3 \%$ to $54,5 \%$ of respondents.

The range of questions in the questionnaire for the military personnel included also question about physical activities at home (gardening and farm work, household chores, etc.), because the army officer has to be an educator and teacher of young soldiers, demonstrating one's personal attitude to different kind of work, doing the household duties as well. The acquired results show that in 2012, 46.7\% of respondents took part in heavy household chores, i.e., by $10 \%$ more than in the previous and next years.

Nowadays any person has got accustomed to regular use of the public transport. However, the question about the type, how to get to work, was included in order to find out the officers' attitude to such type of physical load. It must be admitted, that only a small part of the respondents choose to go on foot to work, although in such a way they could reduce the need for visiting gym.

As the health and physical work capacities are affected not only by insufficient physical activity, but by harmful habits as well, in the anonymous questionnaire the respondents were asked questions on smoking.

From analysis of the received answers in general, it can be seen that respondents' physical activity in 2012, in comparison to the previous year has increased, and the attitude to health promoting measures has improved. 
SHS Web of Conferences

\section{Conclusions}

1. High and good physical activity level was found $22.7 \%$ to $68.9 \%$ of officers of the National Armed Forces of Latvia in time period analysed.

2. Morning exercises and hardening (fitness) procedures were not popular for military personnel.

3. In study years, it was found that respondents try to follow healthy eating habits and sleep regime.

4. Slight decrease the number of respondents with obese.

5. There is a slight increase of the respondents who are regular smokers from $22.7 \%$ till $27.6 \%$.

\section{References}

[1] Salonen, M., Kokko, J., Tyyskä, J., Koivu, M.,Kyröläinen, H. (2008). Military operational stress in 72-hour training of reconnaissance patrolling. 13 th annual congress of the ECSS, 9-12 July 2008 (pp. 647-648). Estoril, Portugal.

[2] Taskanen, M., Uusitalo, A., Kyröläinen, H., Häkkinen, K. (2008). Aerobic Fitness, Body composition, Serum cortisol concentration are associated with symptoms of overloading produced by stressful military training. $13^{\text {th }}$ annual congress of the ECSS, 9-12 July 2008 (p.547). Estoril, Portugal.

[3] Antson, H., Märks, H. (2007). Reappeared and new overuse injuries in conscripts caused by different kinds of duty in unit of Estonian Army. 12 th annual congress of the ECSS,11-14 July 2007 (pp. 421 422). Jyväskylä, Finland.

[4] Caspersen, C.J. , Powell, K.E., Christtenson, G.M. (1985). Physical activity,exercise, and physical fitness:definitions and distinctions for health-related research. Public Health Rep. 100, 125-131.

[5] Dishman, R., Flemmunig, D., Kjaer, M. (2007). Why exercise? $12^{\text {th }}$ annual congress of the ECSS, 11-14 July 2007 (p.1). Jyväskylä, Finland.

[6] Labalaiks, Z., Dravnieks, J. (2008). The control model of physical fitness at the national armed forces of Latvia. 13 th annual congress of the ECSS, 9-12 July 2008 (p.229). Estoril, Portugal.

[7] Antson, H., Märks, H. (2008). The diseases of the musculoskeletal system and conscripts“ physical readiness related to this in the unit of the Estonian Army. $13^{\text {th }}$ annual congress of the ECSS, 9-12 July 2008 (pp 575-576). Estoril, Portugal.

[8] Nascimento, R., Martinez, E., De Sa Rego Fortes.(2008). Relationship between physical fitness body fat mass and coronary risk factors in military Brazilian males. $13^{\text {th }}$ annual congress of the ECSS, 9-12 July 2008 (p.110). Estoril, Portugal.

[9] Fear, N.T., Sundin, J., Rona, R.J. Obesity in the United Kingdom Armed Forces : Prevalence Based on Measured and Self-Reported Data (2011). Military Medicine 176, 44-49.

[10] Contramestre, J., Marques, A., Alves Diniz, J., Carreiro da Costa, F.(2007) Relationship between objective fitness evaluation and perception of health and fitness in the Portuguese military academy students (p. 384). 12 $2^{\text {th }}$ annual congress of the ECSS, 11-14 July 2007. Jyväskylä, Finland. 